\title{
Erratum to: $S$-(3-Aminobenzanthron-2-yl)cysteine in the globin of rats as a novel type of adduct and possible biomarker of exposure to 3-nitrobenzanthrone, a potent environmental carcinogen
}

\author{
Igor Linhart $^{1}$ (D) Iveta Hanzlíková $^{2} \cdot$ Jaroslav Mráz $^{2} \cdot$ Śárka Dušková $^{2}$
}

Published online: 20 May 2017

(C) Springer-Verlag Berlin Heidelberg 2017

\section{Erratum to: Arch Toxicol}

\section{DOI 10.1007/s00204-017-1943-8}

When the above article was first published online, two data points were missing in Figs. 2 and 3 showing curves of elimination of $S$-(3-Aminobenzanthron-2-yl)cysteine (3-ABA-Cys) from globin and plasma, respectively. The missing data points were as follows: day 15 at the dose of $1 \mathrm{mg} / \mathrm{kg}$ in Fig. 2, and day 2 at the dose of $2 \mathrm{mg} / \mathrm{kg}$ in Fig. 3.

The corrected Figs. 2 and 3 are shown below.

The online version of the original article can be found under doi:10.1007/s00204-017-1943-8.

Igor Linhart

linharti@vscht.cz

Department of Organic Chemistry, Faculty of Chemical Technology, University of Chemistry and Technology, Prague, Technická 5, 16628 Prague, Czech Republic

2 National Institute of Public Health, Prague, Šrobárova 48, 10042 Prague, Czech Republic

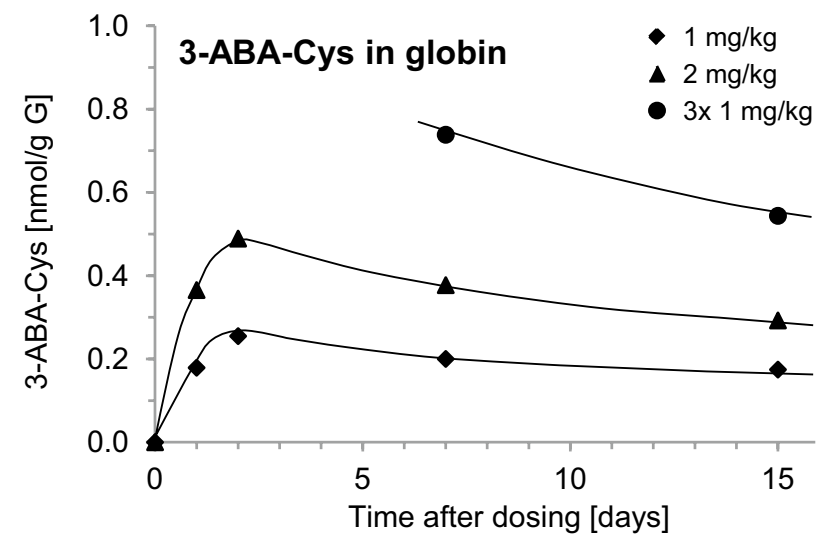

Fig. 2 3-ABA-Cys in globin of rats dosed with 3-NBA. Each point represents mean of the values obtained from two rats

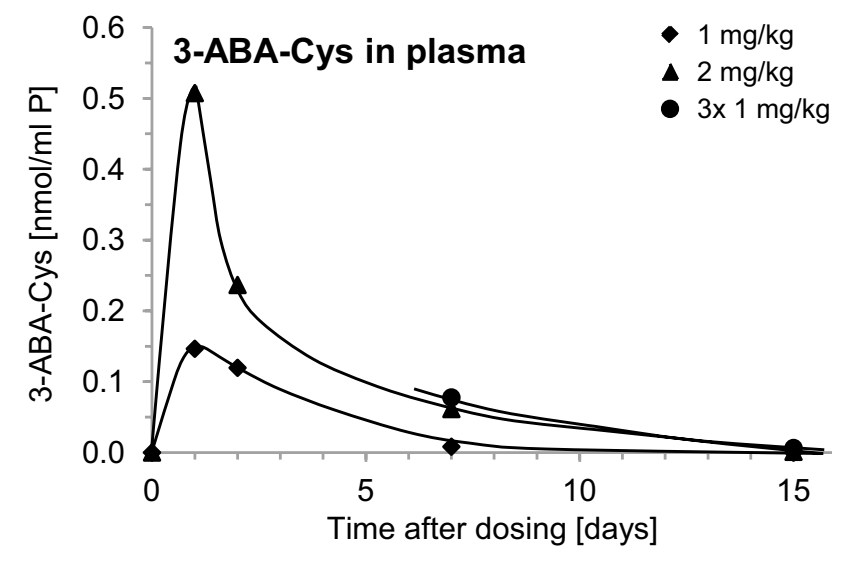

Fig. 3 3-ABA-Cys in plasma of rats dosed with 3-NBA. Each point represents mean of the values obtained from two rats 